\title{
Erratum to: Dynamics and curl ratio of a curling stone
}

\author{
Norikazu Maeno
}

Published online: 30 August 2013

(C) International Sports Engineering Association 2013

\section{Erratum to: Sports Eng}

DOI 10.1007/s12283-013-0129-8

In the original version, the title and unit in Figs. 3, 4, 9, 12 and 14 have been incorrectly published as $X_{\mathrm{m}}$ and $Y_{\mathrm{m}}$. The correct titles are $X$ and $Y$, and the unit is $\mathrm{m}$, as shown in the correct figures below.
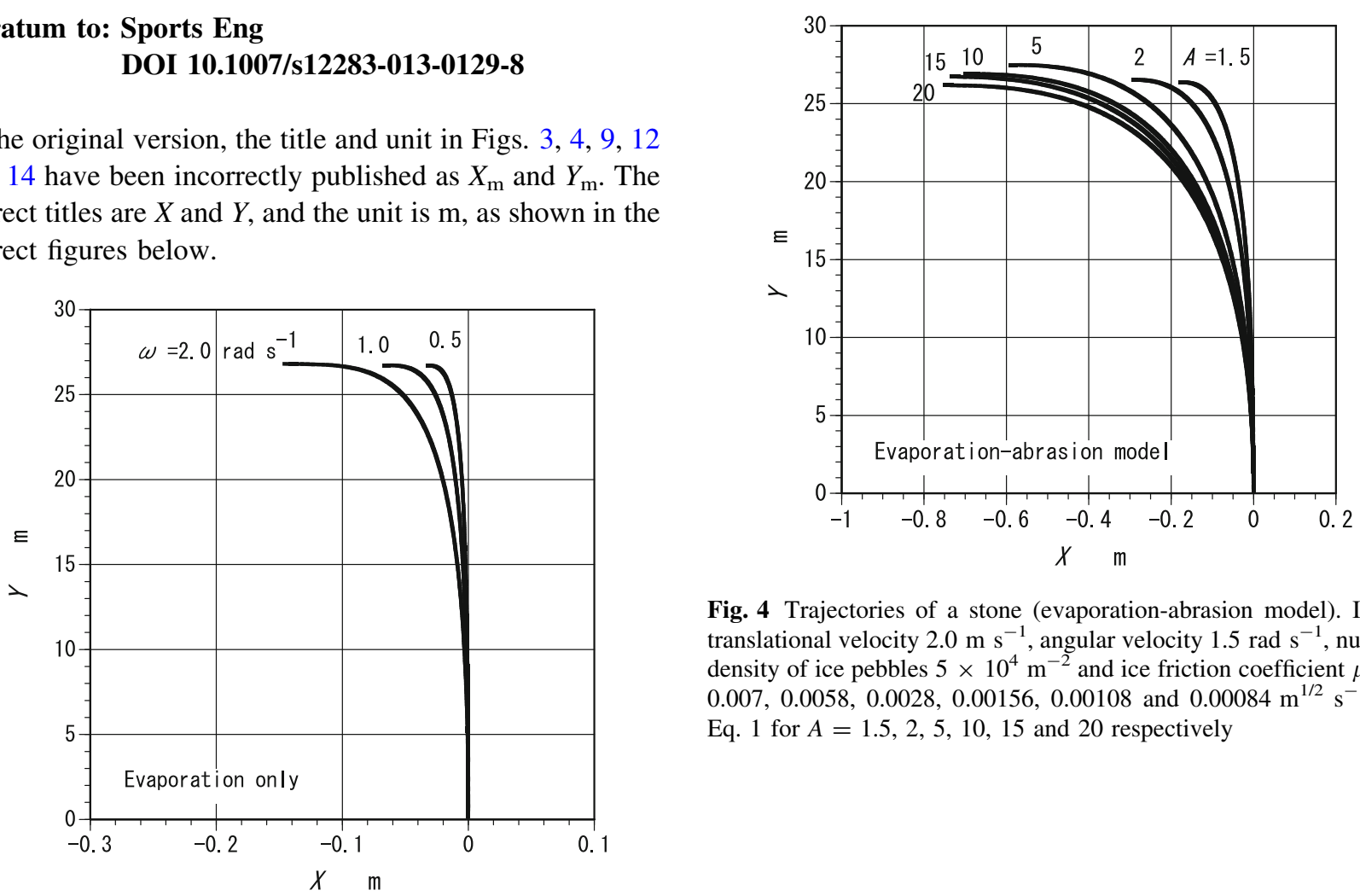

Fig. 4 Trajectories of a stone (evaporation-abrasion model). Initial translational velocity $2.0 \mathrm{~m} \mathrm{~s}^{-1}$, angular velocity $1.5 \mathrm{rad} \mathrm{s}^{-1}$, number density of ice pebbles $5 \times 10^{4} \mathrm{~m}^{-2}$ and ice friction coefficient $\mu_{00}=$ $0.007,0.0058,0.0028,0.00156,0.00108$ and $0.00084 \mathrm{~m}^{1 / 2} \mathrm{~s}^{-1 / 2}$ in Eq. 1 for $A=1.5,2,5,10,15$ and 20 respectively

Fig. 3 Trajectories of a stone (evaporation mechanism). Initial translational velocity, $2.0 \mathrm{~m} \mathrm{~s}^{-1}$, number density of ice pebbles, $5 \times 10^{4} \mathrm{~m}^{-2}$ and ice friction coefficient, Eq. 1 with $\mu_{00}=0.008 \mathrm{~m}^{1 / 2} \mathrm{~s}^{-1 / 2}$

The online version of the original article can be found under doi:10.1007/s12283-013-0129-8.

N. Maeno $(\square)$

Professor Emeritus of Hokkaido University,

Hanakawa Minami 7-2-133, Ishikari,

Hokkaido 061-3207, Japan

e-mail: maenony@ybb.ne.jp 


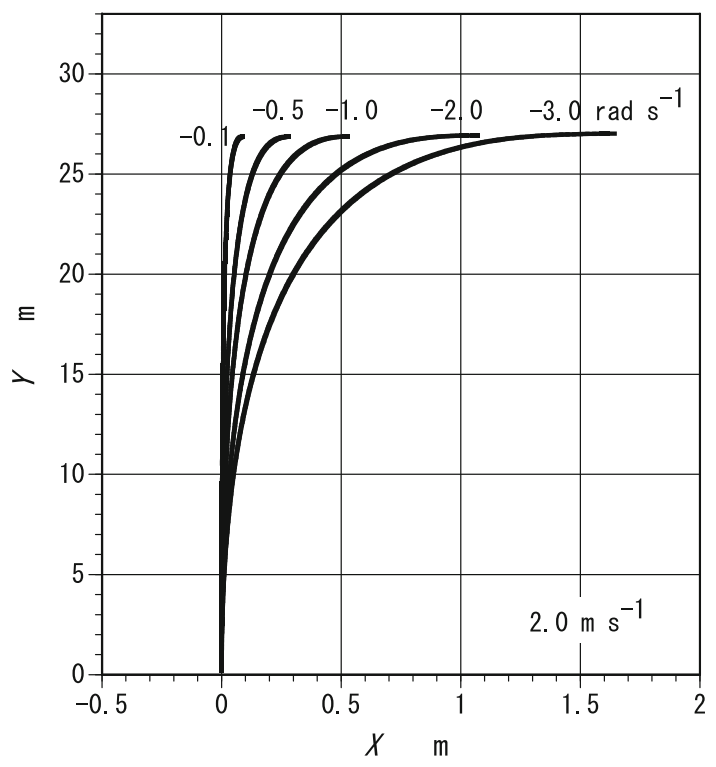

Fig. 9 Trajectories at different angular velocities. Number density of ice pebbles $5 \times 10^{4} \mathrm{~m}^{-2}$, ice friction coefficient $\mu_{00}=0.00156 \mathrm{~m}^{1 / 2}$ $\mathrm{s}^{-1 / 2}$ in Eq. 1, and $A=10$. Initial translational velocity $2.0 \mathrm{~m} \mathrm{~s}^{-1}$

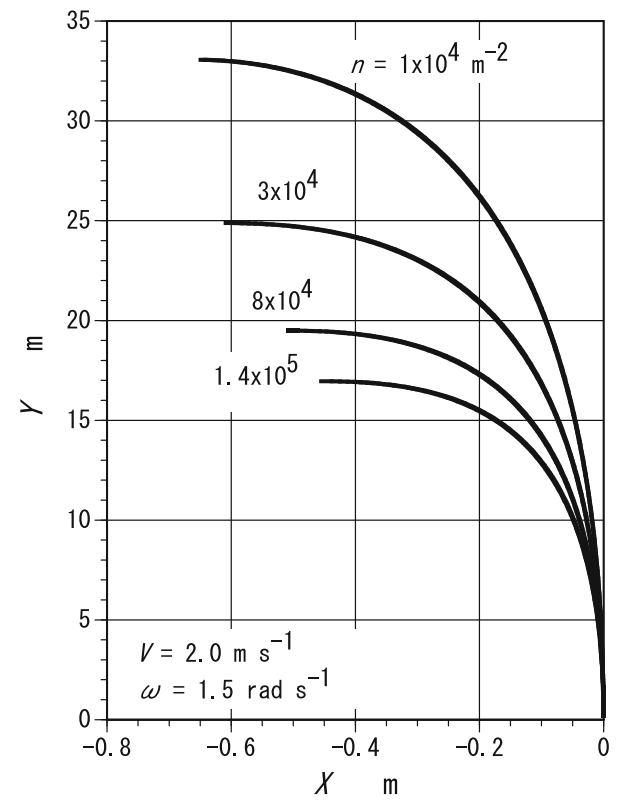

Fig. 12 Trajectories at different pebble densities. Parameters are the same as in Fig. 11. Initial translational velocity $2.0 \mathrm{~m} \mathrm{~s}^{-1}$

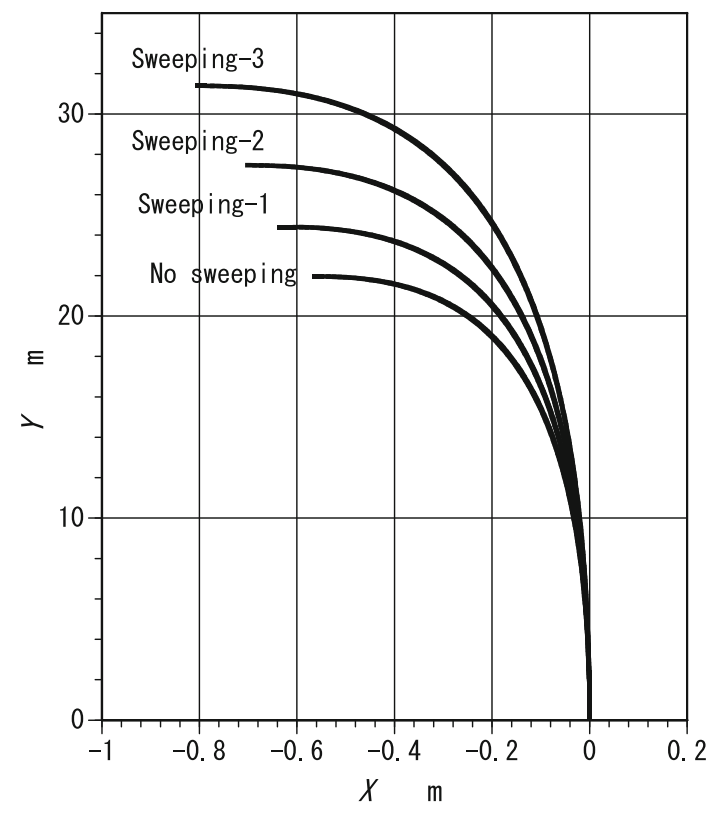

Fig. 14 Effect of sweeping on trajectory. Initial translational velocity $2.0 \mathrm{~m} \mathrm{~s}^{-1}$, and other parameters are the same as in Fig. 13 